\title{
Project risk management using multiple criteria decision-making technique and decision tree analysis: a case study of Indian oil refinery Prasanta Kumar Dey
}

\section{Introduction}

The success parameters for any project are on time completion, within specific budget and with requisite performance (technical requirement). The main barriers for their achievement are the changes in the project environment (Chapman 2006). The problem multiplies with the size of the project as uncertainties in project outcome increase with size (Zayed et al. 2008). Oil refinery construction projects are exposed to uncertain environment because of such factors as planning and design complexity, presence of various interest groups (project owner, owner's project group, consultants, contractors, vendors, etc.), resource (materials, equipment, funds, etc.) unavailability, climatic environment, the economic and political environment and statutory regulations (Dey and Ramcharan 2008). Other risk factors include the complexity of the project, the speed of its construction, the location of the project and its degree of unfamiliarity.

Today's project managers believe that a conventional approach to project management is not sufficient, as it does not enable the project management team to establish an adequate relationship among all phases of project, to forecast project achievement for building confidence of the project team, to make decisions objectively with the help of an available database, to provide adequate information for effective project management and to establish close co-operation among project teams (Dey 2010). Although today's organisations appreciate the benefits of managing risks in construction projects, formal risk analysis and management techniques are rarely used due to lack of knowledge and doubts on the suitability of these techniques for construction industry activities (Kwak and Anbari 2009).

The current literature on construction project risk management consists of mainly four types of work - standards for risk management practices, project risk management practices of countries including ranking of risk factors, case studies of organisations and industries using conceptual mathematical models and applications of risk responses.

Risk management principles and guidelines (the Project Management Body of Knowledge (PMBoK) of Project Management Institute (PMI 2008) and AS/NZS ISO 31000:2009) are the most popular sources for generic project risk management processes. Although they are effective in identifying resources, tools and techniques, and outputs, each project needs a customised approach for application. Wang et al. (2004) study risk management practices of developing countries to identify, categorise, evaluate and rank risks, Thuyet et al. (2007) demonstrate risk management practices in oil and gas construction projects in Vietnam, Zayed et al. (2008) show risks that are inherent in Chinese highway projects, and Dey (2010) illustrates risks in Indian construction projects in oil industry. Although these give the ideas of risk factors, risk management practices, and issues and challenges of applications for construction projects in specific industry and country, they do not provide a framework for application. The project risk management literature is very strong in applying quantitative modelling for analysing risks. Schatteman et al. (2008) uses an integrated computerised risk identification and analysis method. However, their model does not integrate mitigating measures. Tuysuz and Kahraman (2006) develop a risk management framework using fuzzy analytic hierarchy process (AHP) and apply it in information technology project. Tah and Carr (2000) apply fuzzy logic for risk assessment in construction project. However, they did not integrate risk assessment with response development. Wang et al. (2004) apply qualitative risk management model for managing project risk in developing countries, which has very weak integration across risk management processes. There are numerous studies on managing risks as a part of managing overall project (Dey 2006, Shen et al. 2006, Dey and Ramcharan 2008). William (1995) reviews decision support systems (DSS) for managing project risk covering identification, analysis and response development and risk control. This review demonstrates state-of-the-art methods for risk management from early 1980s till middle of 1990s. Although the conventional risk management methods contribute furthering 
risk management practices in construction industry, more practical approach is needed. Additionally, according to author's knowledge, there is no other quantitative framework, which integrates risk identification, analysis and response development. This study contributes a new integrated risk management heuristic, which enables identification, analysis, response development and controlling of risk throughout the project phases. Hence, this study bridges the gaps.

The objective of the study is to develop a DSS which integrates risk identification, analysis and responses development for managing construction project risks. This enables project managers to make the right decision to accomplish project goals. The organisation of this article is as follows: Section 2 briefs the literature on project risk management practices and frameworks, Section 3 states the methodology, Section 4 introduces the proposed framework for risk management, Section 5 demonstrates application of the proposed framework, Section 6 demonstrates the validation of the framework, Section 7 provides the discussion and Section 8 concludes the study.

\section{Literature review}

Risk management is an expanding field, growing beyond the rich work done in finance and insurance (Wu and Olson 2009a). Research has revealed that risk management can be used as a tool for greater rewards and not just to control against loss ( $\mathrm{Wu}$ and Olson 2008). Risk management techniques have been adopted by many researchers in varied areas - Liu et al. (2009) for modelling competitive aspects of distribution channels, Xie et al. (2009) for developing technology to aid in risk control across supply chain, Yang et al. (2009) and Oehmen et al. (2009) for managing supply chain risk and Wu and Olson (2009b) for managing enterprise risk. Stefansson et al. (2009) demonstrates procedure for reducing the risk of delayed delivery in make-to-order production environment.

As per PMBoK (PMI 2008), risk management is the systematic process of identifying, analysing and responding to project risk. It includes maximising the probability and consequences of positive events and minimising the probability and consequences of adverse events to project objectives. Risk management has six steps. They are risk management planning, risk identification, qualitative risk analysis, quantitative risk analysis, risk response planning, risk monitoring and control (PMI 2008). The AS/NZS ISO 31000:2009 sets out five steps for risk management establish the context, identify the risks, analyse the risks, evaluate the risks and treat the risks.

Although risk management standards are helpful to undertake risk management process, they do not help to choose right tools for risk identification and analysis. Moreover, it does not provide any clue on risk factors/events that might need to address in order to manage projects effectively.

In the past, a number of systematic models have been proposed for use in the risk-evaluation phase of the risk management process. Kangari and Riggs (1989) classified these methods into two categories: classical models (i.e. probability analysis and Monte Carlo simulation) and conceptual models (i.e. fuzzy set analysis). They noted that probability models suffer from two major limitations. Some models require detailed quantitative information, which is not normally available at the time of planning, and the applicability of such models to real project risk analysis is limited, because agencies participating in the project have a problem with making precise decisions. The problems are ill-defined and vague, and they thus require subjective evaluations, which classical models cannot handle. There is, therefore, a need for a subjective approach to project risk assessment, with there being the necessary objectivity in the methodology. The AHP, as shown by Mustafa and Al-Bahar (1991) and Dey et al. (1994), provides both a subjective and objective approach to risk analysis using expert judgement. However, their approaches fail to integrate risk analysis with the project management processes.

Recently, Zayed et al. (2008) apply the AHP for assessing risk in Chinese highway projects. The framework prioritises risk factors and ranks alternative projects. However, their approach does not discuss on managing risk during planning and implementation phases of the projects as indicated in the project risk management standards (PMI 2008, AS/NZS ISO 31000:2009). 
Wang et al. (2004) introduce a risk management framework named 'Alien Eyes' risk model, which shows the hierarchical levels of the risks and the influence relationship among the risks. Build on their findings, a qualitative risk mitigation framework has finally proposed. This framework also suffers from integrated objective approach to risk management. Schatteman et al.'s (2008) integrated computerised risk management model identifies and quantifies (probability and impact) schedule risk, but fails to integrate mitigating measures. Shen et al. (2006) suggest public private partnership to manage risks in public sector projects in Hong Kong. While this study contributes on means for risk management, but helps little to analyse risks. Tuysuz and Kahraman (2006) demonstrate a project risk evaluation method using fuzzy AHP approach in information technology projects. Like other studies, it also does not objectively integrate the risk mitigating measures with risk analysis results. Dey (2006) and Dey and Ramcharan (2008) suggest multiple criteria decision-making method for minimising risk by selecting right projects. Although their methods are effective for project selection, they do not tell how to manage risks across the various phases of project. Moreover, they do not determine either probability or impact of risk on project outcomes. Dey (2010) introduces a hierarchical framework for risk analysis. It identifies risks using brainstorming, derives probability using the AHP, and determines impact using risk maps in project, work package and activity level separately. Subsequently, it develops risk mitigating measures for each level using collective experience of the project executives. Although this method provides a practical approach to project risk management, lacks objective derivation of risk responses. Dey (2001, 2002) introduces integrated frameworks for project risk management which takes generic project risk management steps - identification, analysis and response development and applies the AHP for risk analysis. The present framework is an extension to these works with integrated risk identification using cause and effect diagram, analysis using the AHP, response development using risk map and selecting mitigating measures using decision tree analysis.

The proposed approach to project risk management introduces a comprehensive and innovative framework which integrates four methods - cause and effect diagram for risk identification, the AHP for determining probability of risks, risk map for deriving risk impact, and decision tree for revealing risk mitigating measures. Therefore, this study bridges the gaps in current literature.

\section{Methodology}

This study adopts case study approach. First, review of project risk management was undertaken to analyse pros and cons of contemporary approaches to project risk management. Second, a conceptual framework for project risk management was proposed. Third, the proposed framework was then applied to a grass-root oil refinery construction project in India. Fourth, the pros and cons of the framework were revealed. Fifth, the practical implication of the proposed framework was validated through the focus group with representatives of a few executives from the Indian oil industry.

The proposed risk management framework uses cause and effect diagram to identify risk, the AHP to derive probability of occurrence of risk, risk map to determin impact, and decision tree analysis to objectively reveal measures for risk mitigation. The following paragraphs demonstrate the AHP and decision tree briefly.

The AHP developed by Saaty (1980) provides a flexible and easily understood way of analysing complicated problems. It is a multiple criteria decision-making technique that allows subjective as well as objective factors to be considered in the decision-making process. The AHP allows the active participation of decision-makers in reaching agreement, and gives managers a rational basis on which to make decisions. AHP is based on the following three principles: decomposition, comparative judgement and synthesis of priorities.

The AHP is a theory of measurement for dealing with quantifiable and intangible criteria that has been applied to numerous areas, such as decision theory and conflict resolution (Vargas 1990). AHP is a problem-solving framework and a systematic procedure for representing the elements of any problem (Saaty 1983).

Formulating the decision problem in the form of a hierarchical structure is the first step of AHP. In a typical hierarchy, the top level reflects the overall objective (focus) of the decision problem. The elements affecting the decision are represented in intermediate levels. The lowest level comprises the decision options. Once a hierarchy is 
constructed, the decision-maker begins a prioritisation procedure to determine the relative importance of the elements in each level of the hierarchy. The elements in each level are compared as pairs with respect to their importance in making the decision under consideration. A verbal scale is used in AHP that enables the decisionmaker to incorporate subjectivity, experience and knowledge in an intuitive and natural way. After comparison matrices are created, relative weights are derived for the various elements. The relative weights of the elements of each level with respect to an element in the adjacent upper level are computed as the components of the normalised eigenvector associated with the largest eigenvalue of their comparison matrix. Composite weights are then determined by aggregating the weights through the hierarchy. This is done by following a path from the top of the hierarchy to each alternative at the lowest level, and multiplying the weights along each segment of the path. The outcome of this aggregation is a normalised vector of the overall weights of the options. The mathematical basis for determining the weights was established by Saaty (1980).

Risk management is usually a team effort, and the AHP is one available method for forming a systematic framework for group interaction and group decision-making (Saaty 1982). Dyer and Forman (1992) describe the advantages of AHP in a group setting as follows: (1) both tangibles and intangibles, individual values and shared values can be included in an AHP-based group decision process, (2) the discussion in a group can be focused on objectives rather than alternatives, (3) the discussion can be structured so that every factor relevant to the discussion is considered in turn and (4) in a structured analysis, the discussion continues until all relevant information from each individual member in a group has been considered and a consensus choice of the decision alternative is achieved. A detailed discussion on conducting AHP-based group decision-making sessions including suggestions for assembling the group, constructing the hierarchy, getting the group to agree, inequalities of power, concealed or distorted preferences, and implementing the results can be found in Saaty (1982) and Golden et al. (1989). For problems with using AHP in group decision-making, see Islie et al. (1991). Appendix 1 shows general formulations for determining importance of criteria for decision-making, eigen vectors, consistency ratio through calculating $\lambda$ max.

Decision trees use calculations of expected monetary values (EMVs) to measure the attractiveness of alternatives. Decision trees, however, use graphical models as well to display several relevant aspects of a decision situation. These graphical models consist of tree-like structures (hence the name) with branches to represent the possible action-event combinations. The conditional payoff is written at the end of each branch. A tree gives much the same information as a matrix, but, in addition, it can be used to depict multiple-stage decisions - a series of decisions over time (Dilworth 2000). The decision tree approach (DTA) logically structures risk management philosophy by identifying alternative responses in mitigating risk. It provides a basis for quantitative risk management and incorporates management perceptions.

\section{The proposed risk management framework}

The proposed risk management framework has 10 steps. First, a work breakdown structure is formed in order to identify all the work packages. This facilitates to identify risk factors specific to each work package for better control. Second, the factors that affect the time, cost and quality achievement of specific work packages are identified using cause and effect diagrams. Third, a hierarchical risk structure is formed in the AHP framework with the consideration of all risk factors that are likely to affect entire project. Fourth, the likelihood of their occurrences is determined using the AHP. It comprises of comparing the risk factors pairwise to determine the likelihood of their occurrences, comparing the risk sub-factors pairwise to determine likelihood of their occurrences, comparing the alternative work packages with respect to each sub-factor in order to determine the likelihood of their failure from the risk sub-factor and synthesising the results across the hierarchy in order to derive relative overall chance of failure of each work package. Fifth, the severity (probability and impact) of each factor is then derived through guesstimating. Sixth, the expected time and cost overrun of the project is then formulated using probability theory. Possible alternative responses for mitigating the effect of risk factors are revealed and the cost for each response is estimated. Seventh, decision trees for each work package are drawn in order to show the possible responses with the likelihood of time and cost overrun. Eighth, risk responses are evolved. Ninth, the EMV (cost of risk response in this case) is calculated for selecting the best option through statistical analysis. Finally, the selected best options are implemented. 
Figure 1 shows the proposed construction risk management framework.

Figure 1. Proposed framework for project risk management in a quantitative framework using a combined AHP and DTA.

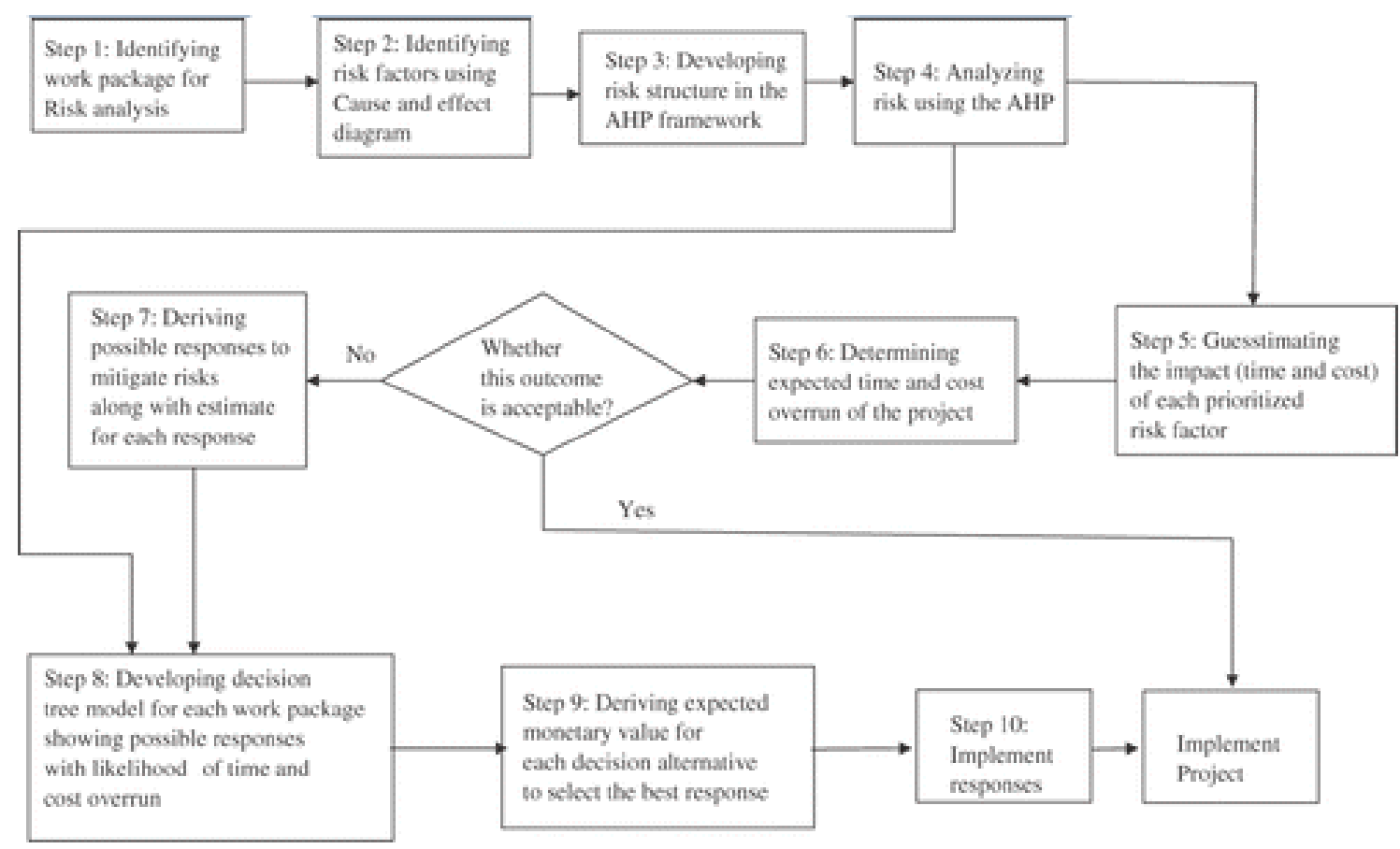

\section{Application}

The proposed risk management framework was applied in case of the construction of a new oil refinery of 7.5 million metric ton per annum capacity in the Central part of India. The project cost was estimated at US\$ 600 million.

A risk management group was formed for managing risk for the case study project. The group consisted of one member (with more than 15 years experience) each from Mechanical, Electrical, Civil, Tele-communication and instrumentation, Finance and Materials of the project function of the concerned organisation. They were entrusted for collecting data, analysing, interpreting and preparing recommendations with active interactions with the core project implementation team.

The following paragraphs demonstrate each step of the proposed risk management framework.

\section{Step 1}

Identifying the work packages for risk analysis

The total project scope was hierarchically arranged to form a work break down structure. Figure 2 shows the work breakdown structure of the oil refinery construction project under study. The risk management group brainstormed on the complexity in design, implementation and operations of each package using their experience. According to the complexity in achieving time, cost and quality targets, the work packages that were considered for risk management were Instrumentation and control room, Process equipment and piping, Tank farm, pipelines and loading/unloading facilities, and Power and utilities. 
Figure 2. Work Breakdown Structure.

Project: Constructing a 7.5 MMTPA

Oil Refinery

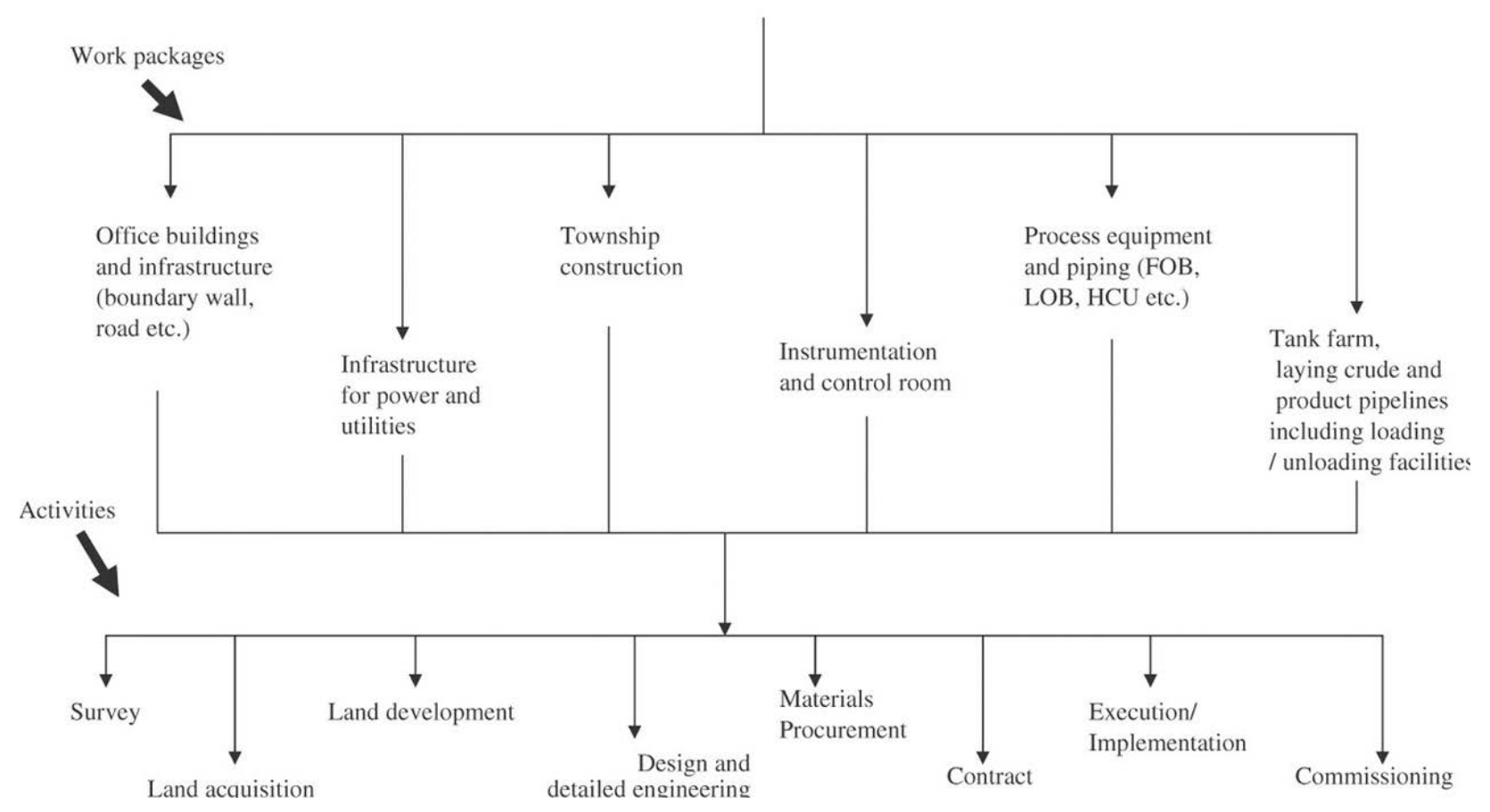

Step 2

Identifying risk factors that affect time, cost and quality achievement of specific work packages using cause and effect diagrams

The risk factors and sub-factors were then identified using a cause and effect diagram for each package separately by the project executives, who were actively involved for managing those packages through focus group discussions with facilitation of the risk management group. The risk management group then compiled the risk factors and subfactors to develop a consolidated list of risk factors and sub-factors for the entire project. Figure 3 shows the cause and effect diagram for the risk of the project under study as identified by the risk management group.

Figure 3. Risk identification using cause and effect diagram.

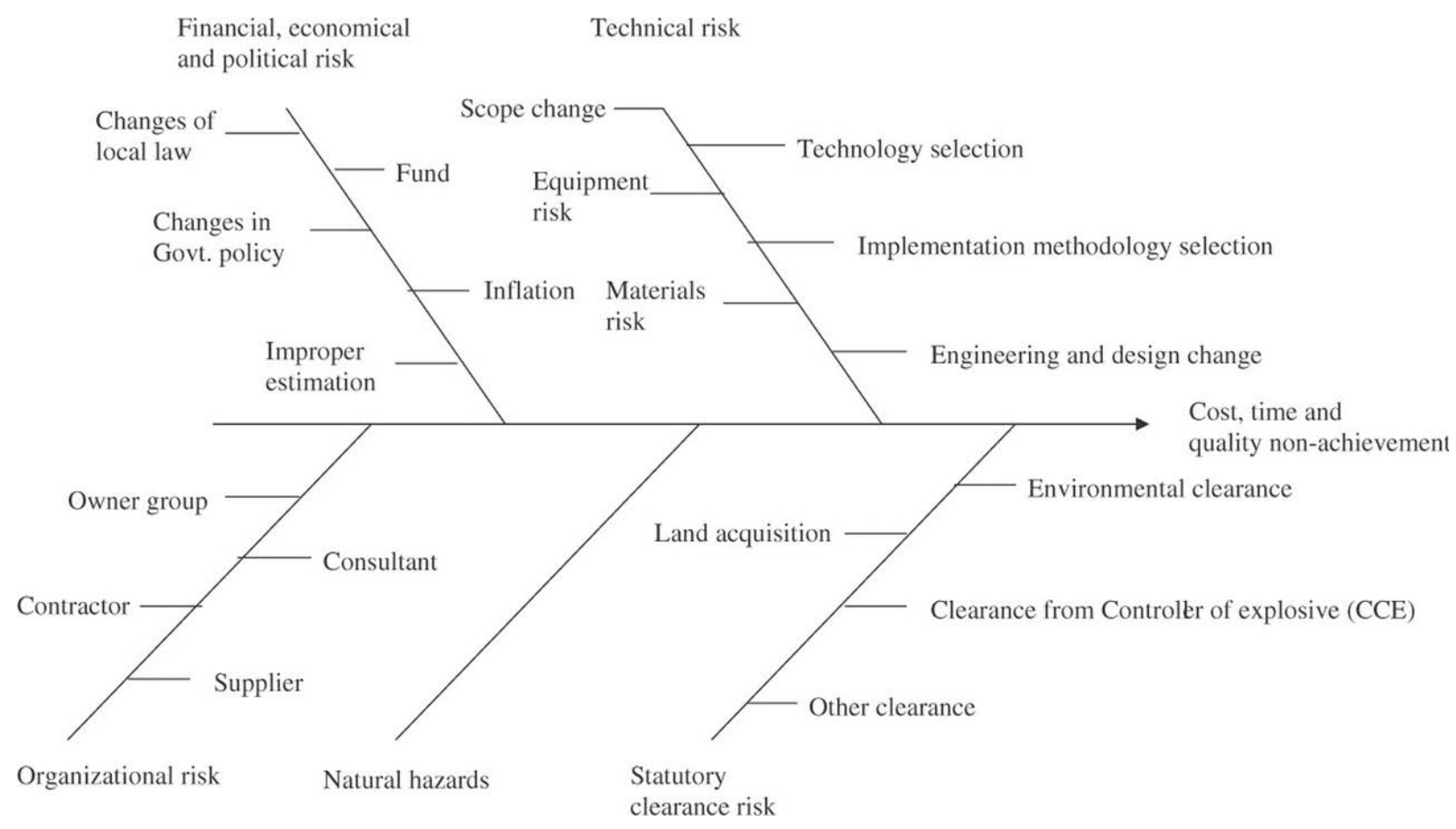


The following paragraph describes the risk factors briefly.

Oil refinery construction projects deploy complex technologies, which make it vulnerable to failure in terms of time, cost and quality achievement. There is always a chance of changing project scope, as accurate project plan is almost impossible to formulate (Dey 2010). The successful accomplishment of projects depends on how effectively these changes are managed. Selecting appropriate technologies, implementing them effectively and operating them efficiently are the key success factors for business (Thuyet et al. 2007). However, any project will have uncertainties to achieve those. Other than the above internal factors, projects are always vulnerable from external factors like financial, political and economical risk (Chapman 2006). Availability of fund throughout project life and stability of political and economic environment impact project significantly. Additionally, accuracy of available information for project cost estimate could also affect project outcomes (Zayed et al. 2008). Additionally, number of stakeholders is involved in large scale construction projects such as oil refinery construction. Their individual and collective capabilities contribute largely for successful completion of the projects. Historically, natural hazards are one of the major causes of project failure. These include rain, flood, subsidence, fire and heat for the project under study. Large infrastructure projects need regulatory clearances from many competent authorities, which include environment clearance, land acquisition related clearance, explosive fire clearance and construction clearance. On time approval of those clearances is critical to complete the construction activities on time (Wang et al. 2004).

Step 3

Developing the risk structure in the AHP framework

The factors as identified in previous steps were arranged hierarchically to form an analytical framework. Figure 4 shows the hierarchical structure for risk analysis of oil refinery construction project. The level 1 is the goal, i.e. 'determining riskiness of project'. Levels 2 and 3 are the factors and sub-factors, respectively, as identified by the project risk management group. Level 4 contains the alternatives, i.e. critical work packages as identified by the same group.

Figure 4. The AHP model for determining riskiness of project.

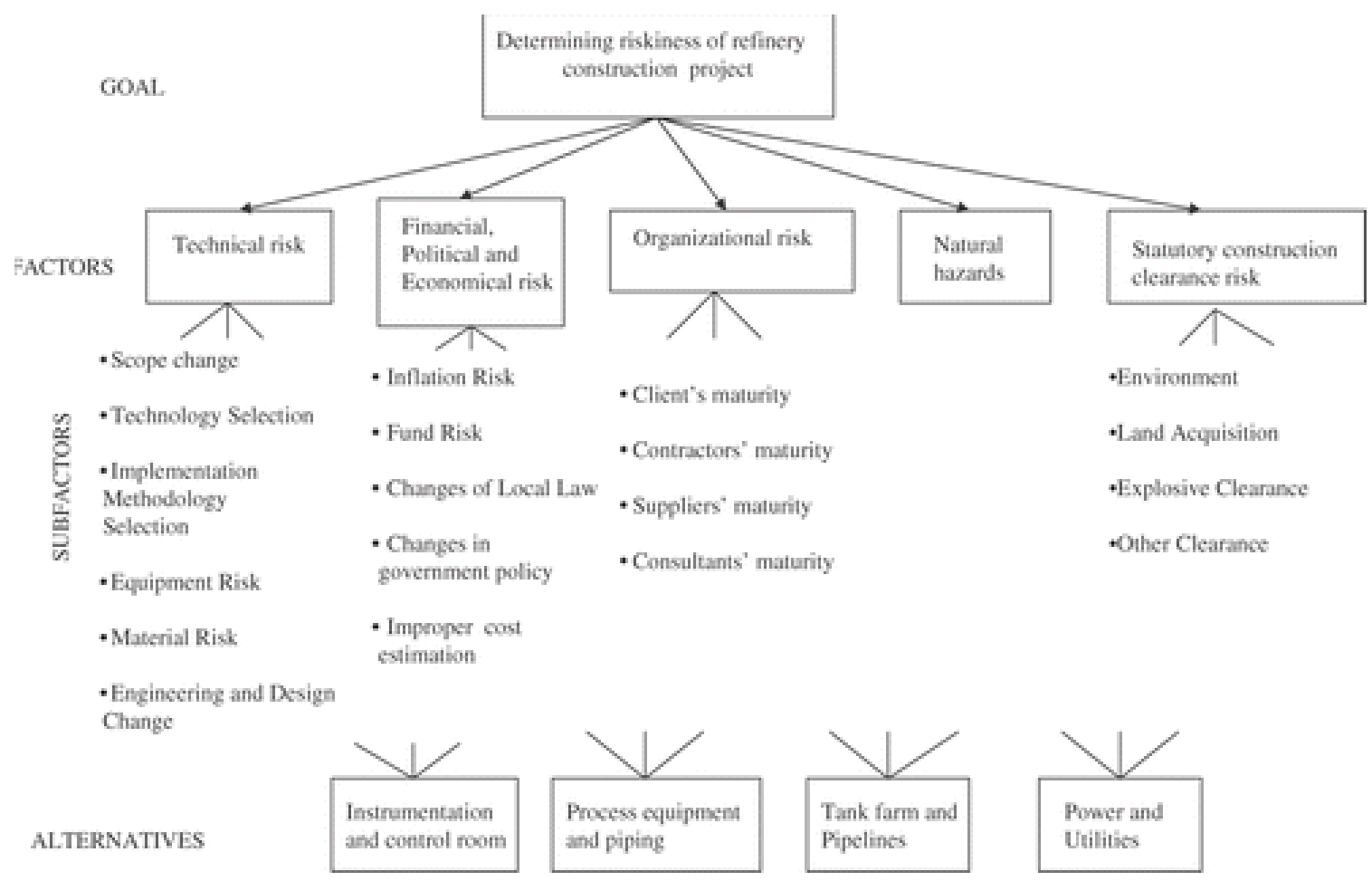

Step 4 (4.1-4.4)

Analysing risk using the AHP 
Risk analysis of the project was then carried out using the Expert Choice (Forman and Saaty 1983) (http://www.expertchoice.com/). The risk management group in a focus group made pairwise comparisons in both factor (Table 1) and sub-factor levels (Appendix 2) using the verbal scale (Table 2) developed by Saaty (1980) in order to determine the likelihood of their occurrences. As for example, for the factor level comparison, the risk management group agreed that 'technical risk' was 'moderately important/vulnerable' compared to 'financial and economical risk'. Accordingly, they used ' 3 ' in the second row and third column, and ' $1 / 3$ ' in the third row and second column. Subsequently, they compared each alternative work package with respect to each risk sub-factor in order to determine the likelihood of failure of each work package due to occurrences of those risks (Appendix 3). The analysis was done using group consensus. Using the Expertchoice, the results were synthesised across the hierarchy to determine the likelihood of failure of the work packages. Table 3 gives the outcomes of pairwise comparison in factor, sub-factor and alternative levels along with the overall likelihood of failure of each work package. The detailed calculation of the AHP application is available on request.

Table 1. Comparison matrixes in factor level using information from Table 2.

\begin{tabular}{|c|c|c|c|c|c|c|}
\hline Factors & \begin{tabular}{|} 
Technical \\
risk
\end{tabular} & $\begin{array}{l}\text { Financial and } \\
\text { economical } \\
\text { risk }\end{array}$ & $\begin{array}{c}\text { Organisational } \\
\text { risk }\end{array}$ & $\begin{array}{l}\text { Natural } \\
\text { hazards }\end{array}$ & $\begin{array}{l}\text { Statutory } \\
\text { clearance } \\
\text { risk }\end{array}$ & \\
\hline Technical risk & 1 & 3 & 4 & 5 & 5 & \\
\hline Financial and economical risk & $1 / 3$ & 1 & 2 & 3 & 3 & \\
\hline Organisational risk & $1 / 4$ & $1 / 2$ & 1 & 2 & 2 & \\
\hline Natural hazards & $1 / 5$ & $1 / 3$ & $1 / 2$ & 1 & 1 & \\
\hline Statutory clearance risk & $1 / 5$ & $1 / 3$ & $1 / 2$ & 1 & 1 & \\
\hline Column sum & 1.9833 & 5.1667 & 8 & 12 & 12 & \\
\hline \multicolumn{7}{|l|}{ Normalised matrix to determine the likelihood of failure from each factor } \\
\hline & & & & & & Likelihood \\
\hline Technical risk & $0.504^{a}$ & 0.581 & 0.500 & 0.417 & 0.417 & $0.484^{\mathrm{b}}$ \\
\hline Financial and economical risk & 0.168 & 0.194 & 0.250 & 0.250 & 0.250 & 0.222 \\
\hline Organisational risk & 0.126 & 0.097 & 0.125 & 0.167 & 0.167 & 0.136 \\
\hline Natural hazards & 0.101 & 0.065 & 0.063 & 0.083 & 0.083 & 0.079 \\
\hline Statutory clearance risk & 0.101 & 0.065 & 0.063 & 0.083 & 0.083 & 0.079 \\
\hline \multicolumn{7}{|c|}{$\begin{array}{l}\text { Notes: }{ }^{a} 1 / 1.9833=0.504 \text { (each cell has been divided by the column sum to form normalized matrix); }{ }^{b} \text { likelihood of risk factors is then determined by averaging the numbers across } \\
\text { each row: Average }(0.504+0.581+0.500+0.417+0.417)=0.484) .\end{array}$} \\
\hline $\begin{array}{l}\lambda_{\max }=1.9833 \times 0.484+5.1667 \times 0.222+8 \times 0.136+12 \times 0.079+12 \times 0.079=5.0914 ; \\
\text { Consistency Index, } C I=\left(\lambda_{\max }-1\right) /(n-1) ; C I=(5.0914-5) /(5-1)=0.02286, \text { where } n \\
=\text { size of square matrix. Consistence Ratio }=(\text { Consistency Index } / \text { Random Index }) \times 100 ; \\
\text { Random Index }=1.12 . \text { Consistency Ratio: } 2.04 \text {, which is less than } 10 \% . \text { Hence it is } \\
\text { acceptable. }\end{array}$ & & & & & & \\
\hline
\end{tabular}

Table 2. Scale of relative importance for pairwise comparison (Saaty 1980).

\begin{tabular}{|l|l|l}
\hline Intensity & \multicolumn{1}{|c}{ Definition } & \\
\hline 1 & Equal importance & Two activities contribute equally to the object \\
\hline 3 & Moderate importance & Slightly favours one over another \\
\hline 5 & Essential or strong importance & Strongly favours one over another \\
\hline 7 & Demonstrated importance & Dominance of the demonstrated importance in practice \\
\hline 9 & Extreme importance & Evidence favouring one over another of highest possible order of affirmation \\
\hline $2,4,6,8$ & Intermediate values & When compromise is needed \\
\hline
\end{tabular}


Table 3. Likelihood of risk in project.

\begin{tabular}{|l|l|l}
\hline Intensity & \multicolumn{1}{|c}{ Definition } & \multicolumn{1}{|c}{ Explanation } \\
\hline 1 & Equal importance & Two activities contribute equally to the object \\
\hline 3 & Moderate importance & Slightly favours one over another \\
\hline 5 & Essential or strong importance & Strongly favours one over another \\
\hline 7 & Demonstrated importance & Dominance of the demonstrated importance in practice \\
\hline 9 & Extreme importance & Evidence favouring one over another of highest possible order of affirmation \\
\hline $2,4,6,8$ & Intermediate values & When compromise is needed \\
\hline
\end{tabular}

The following paragraphs describe the observations from risk analysis:

1. Technical risk was the major risk category for time and cost overrun of the project. Among the technical risks, scope change, engineering and design change, technology and implementation methodology selections were the major causes of project failure. The 'Process equipment and piping' and 'tank farm and pipelines' work packages were vulnerable from scope change. Technology selection was vital for 'instrumentation and control room' and 'power and utility' work packages. Engineering and design change was quite likely to occur for the 'instrumentation and control room' and 'Process equipment and piping' work packages. Prior selection of implementation methodology was crucial for the 'instrumentation and control room' packages, as improper selection could cause major time and cost overrun. Unavailability of pipe materials and delayed delivery of pumping unit could result in considerable time overrun.

2. Other major risks in project achievement were financial, economic and political risk and organisational risk. Within this category, fund flow problems and improper estimation were the major causes of concern. All the packages were equally vulnerable from fund flow problems. However, the 'instrumentation and control room' and 'Process equipment and piping' packages were prone to improper estimates due to more uncertainties in design and implementation methodology selection. Although the organisational risk was less vulnerable for the project under study, the consultant and contractor's capabilities were a bit of a concern to the management of the project. The 'instrumentation and control room' work package was the most susceptible to the consultant and contractor's performance. The capability of the owner's project group was required for achievement of all the work packages.

3. Although the project under study was not very vulnerable from statutory clearance risk, care should be taken for getting environmental clearance and explosive clearance on time for trouble free implementation.

4. Natural hazards were the part and parcel of the oil refinery project as it was exposed many seasons. Although it had less priority compared to other risk factors, almost all the work packages were vulnerable. Accordingly, appropriate contingency plans were developed for each package.

5. The 'Process equipment and piping' work package was the most risky package with a probability of failure of 0.314. The major factors for possible failure were changes in scope, change in engineering and design, fund availability, vendor capability, natural hazard and clearance for land acquisition. The 'Instrumentation and control room' work package with probability of failure 0.276 came next. The main contributing factors were scope change, implementation methodology selection, engineering and design change, and improper estimate thereon. The 'Tank farm and pipelines' and 'Power Utility' work packages were relatively less vulnerable and they had relative failure chances 0.217 and 0.176 , respectively.

\section{Step 5}

Guesstimating the impact (time and cost) of each prioritised risk factor

The risk management group then guesstimated the impact of the risk factors in terms of time and cost overrun. Table 4 gives the probability (from Table 3 ) and impact of all risk factors. 
Table 4. Probability and severity of risk factors.

\begin{tabular}{|c|c|c|c|}
\hline \multirow{2}{*}{ Risk factors } & \multirow{2}{*}{ Probability $^{a}$} & \multicolumn{2}{|c|}{ Impact } \\
\hline & & Time overrun (in months) ${ }^{b}$ & Cost overrun (in million US\$) \\
\hline Scope change & 0.171 & 8 & 90 \\
\hline Technology selection & 0.062 & 6 & 20 \\
\hline Implementation methodology & 0.073 & 3 & 0 \\
\hline Equipment & 0.027 & & \\
\hline Materials & 0.032 & 3 & 0 \\
\hline Engineering and design change & 0.118 & 5 & 30 \\
\hline Inflation & 0.025 & & \\
\hline Fund & 0.112 & 2 & 0 \\
\hline Local law & 0.015 & & \\
\hline Policy & 0.017 & & \\
\hline Cost estimate & 0.053 & 2 & 0 \\
\hline Client & 0.015 & & \\
\hline Contractor & 0.038 & 6 & 30 \\
\hline Supplier & 0.062 & 8 & 30 \\
\hline Consultant & 0.021 & & \\
\hline Natural hazards & 0.079 & 12 & 90 \\
\hline Environmental & 0.006 & & \\
\hline Land acquisition & 0.041 & 4 & 0 \\
\hline Explosive & 0.016 & & \\
\hline Other & 0.016 & & \\
\hline
\end{tabular}

\section{Step 6}

Determining expected time and cost overrun of the project

The above results were then used to derive the expected time and cost overrun using Bayesian probability (Canavos 1984).

Table 5 gives the overall time and cost overrun of the project.

Continuing... 
Table 5. Expected time and cost overrun.

\begin{tabular}{|c|c|c|c|c|c|}
\hline \multirow{2}{*}{ Risk factors } & \multirow{2}{*}{ Probability $^{a}$} & \multicolumn{4}{|c|}{ Impact } \\
\hline & & Time overrun & Cost overrun & Expected time overrun ${ }^{b}$ & Expected cost overrun ${ }^{b}$ \\
\hline Scope change & 0.171 & 8 & 90 & 1.37 & 15.41 \\
\hline Technology selection & 0.062 & 6 & 20 & 0.37 & 1.25 \\
\hline Implementation methodology & 0.073 & 3 & 0 & 0.22 & 0.00 \\
\hline Equipment & 0.027 & & & 0.00 & 0.00 \\
\hline Engineering and design change & 0.118 & 5 & 30 & 0.59 & 3.53 \\
\hline Inflation & 0.025 & & & 0.00 & 0.00 \\
\hline Fund & 0.112 & 2 & 0 & 0.22 & 0.00 \\
\hline Local law & 0.015 & & & 0.00 & 0.00 \\
\hline Policy & 0.017 & & & 0.00 & 0.00 \\
\hline Cost estimate & 0.053 & 2 & 0 & 0.11 & 0.00 \\
\hline Contractor & 0.038 & 6 & 30 & 0.23 & 1.15 \\
\hline Supplier & 0.062 & 8 & 30 & 0.49 & 1.85 \\
\hline Consultant & 0.021 & & & 0.00 & 0.00 \\
\hline Natural hazards & 0.079 & 12 & 90 & 0.95 & 7.10 \\
\hline Environmental & 0.006 & & & 0.00 & 0.00 \\
\hline Land acquisition & 0.041 & 4 & 0 & 0.16 & 0.00 \\
\hline Explosive & 0.016 & & & 0.00 & 0.00 \\
\hline Other & 0.016 & & & 0.00 & 0.00 \\
\hline \multicolumn{4}{|c|}{ Overall expected time and cost overrun } & 4.81 & 30.28 \\
\hline
\end{tabular}

Notes: ${ }^{a}$ Expected time overrun $=0.171 \times 8=1.37 ;{ }^{b}$ expected cost overrun $=0.171 \times 90=15.41$.

The analysis revealed that the project was expected to have experienced 4.81 months delay and US\$ 30.28 million cost overrun.

\section{Step 7}

Deriving possible risk responses

Risk analysis results derived a few risk responses in line with the principles to avoid, to reduce, to transfer and to absorb. The risk management group through a brainstorming session derived the following responses for the project under study:

1. Carrying out a detailed survey with the objective of minimum scope and design change.

2. Selecting technology and implementation methodology on the basis of owner's/consultant's expertise, availability of contractors and vendors and lifecycle costing.

3. Executing design and detailed engineering on the basis of selected technology and implementation methodology and detailed survey.

4. Selecting superior contractors, consultants and vendors on the basis past performance.

5. Scheduling the project by accommodating seasonal calamities.

6. Planning contingencies and acquiring insurance.

7. Ensuring the availability of all statutory clearance before design and detailed engineering.

Table 6 gives the estimated cost of the above risk responses for each work package. Sources for cost data were the detailed feasibility report and cost estimate for the project concerned, based on other recently completed projects and quotations from vendors and contractors. 
Table 6. The cost data (million US\$) for each package against various responses.

\begin{tabular}{|c|c|c|c|c|c|}
\hline Responses & $\begin{array}{l}\text { Tank farm and } \\
\text { pipelines }\end{array}$ & $\begin{array}{l}\text { Process } \\
\text { equipment and } \\
\text { piping }\end{array}$ & $\begin{array}{l}\text { Instrumentation and } \\
\text { control room }\end{array}$ & $\begin{array}{l}\text { Power and } \\
\text { utilities }\end{array}$ & $\begin{array}{l}\text { Office buildings and } \\
\text { plant infrastructure }\end{array}$ \\
\hline $\begin{array}{l}\text { Carrying out detailed survey with the objective of minimum scope and } \\
\text { design change }\end{array}$ & $12^{\mathrm{a}}$ & 6 & 6 & 3 & 3 \\
\hline $\begin{array}{l}\text { Selecting technology and implementation methodology on the basis of } \\
\text { owner's/consultant's expertise, availability of contractors and vendors } \\
\text { and lifecycle costing }\end{array}$ & 3 & 6 & 3 & 1.5 & 1.5 \\
\hline $\begin{array}{l}\text { Executing design and detailed engineering on the basis of selected } \\
\text { technology and implementation methodology and detailed survey }\end{array}$ & 1 & 1 & 1 & 1 & 1 \\
\hline $\begin{array}{l}\text { Selecting superior contractors, consultants and vendors on the basis } \\
\text { past performance }\end{array}$ & 22 & 16 & 10 & 2 & 2 \\
\hline Scheduling project by accommodating seasonal calamities & 6 & - & 5 & - & - \\
\hline Planning contingencies and acquiring insurance & 11 & 2 & 6 & 1 & 1 \\
\hline $\begin{array}{l}\text { Ensuring the availability of all statutory clearance before design and } \\
\text { detailed engineering }\end{array}$ & 1 & 1 & 1 & 1 & 1 \\
\hline Total & 56 & 32 & 32 & 10 & 10 \\
\hline Grand total & \multicolumn{5}{|l|}{140} \\
\hline
\end{tabular}

Notes: ${ }^{a} 14 \mathrm{~km}$ pipeline survey, soil testing for entire tank farm, control valves and control room design and implementation planning cost US\$ 4 million, US\$ 3 million and US\$ 5 million, respectively.

\section{Step 8}

Developing the decision tree model

The next step was to form a decision tree for each work package with the consideration of probability and severity of failure and various possible responses.

The group decided the following decision alternatives:

- $\quad$ Do nothing.

- $\quad$ Carrying out detailed survey (additional).

- $\quad$ Using superior technology.

- $\quad$ Engaging expert project team.

- Implementing all responses as indicated in Table 6.

The decision trees were formulated for the work packages (tank farm and pipelines laying, process equipment and piping, Instrumentation and control room, and power utilities) of the oil refinery construction project under study. The probability and impact (time and cost) for each decision alternative were derived from the risk analysis study of each package and expert opinion through brainstorming.

\section{Step 9}

Deriving EMV for each decision alternative to select the best response

The EMVs were then calculated for each alternative decision for all the packages. Figure 5 shows the decision tree for the work package 'Tank farm and pipelines'. Tables 7-10 show the EMVs for various decision options of the work packages 'Tank farm and pipelines', 'Process equipment and piping', 'Instrumentation and control room', and 'power and utilities', respectively. The cost figures had been taken from Table 6, the probability figures are from Table 3 (it was assumed that if all the responses were under taken the probability of residual risk would be $5 \%$ ), and the effects of risk factors on time and cost after risk response have been estimated from cumulative experience of the risk management group through focus group. 
Figure 5. Decision tree for the work package 'lank Farm and Pipelines'.

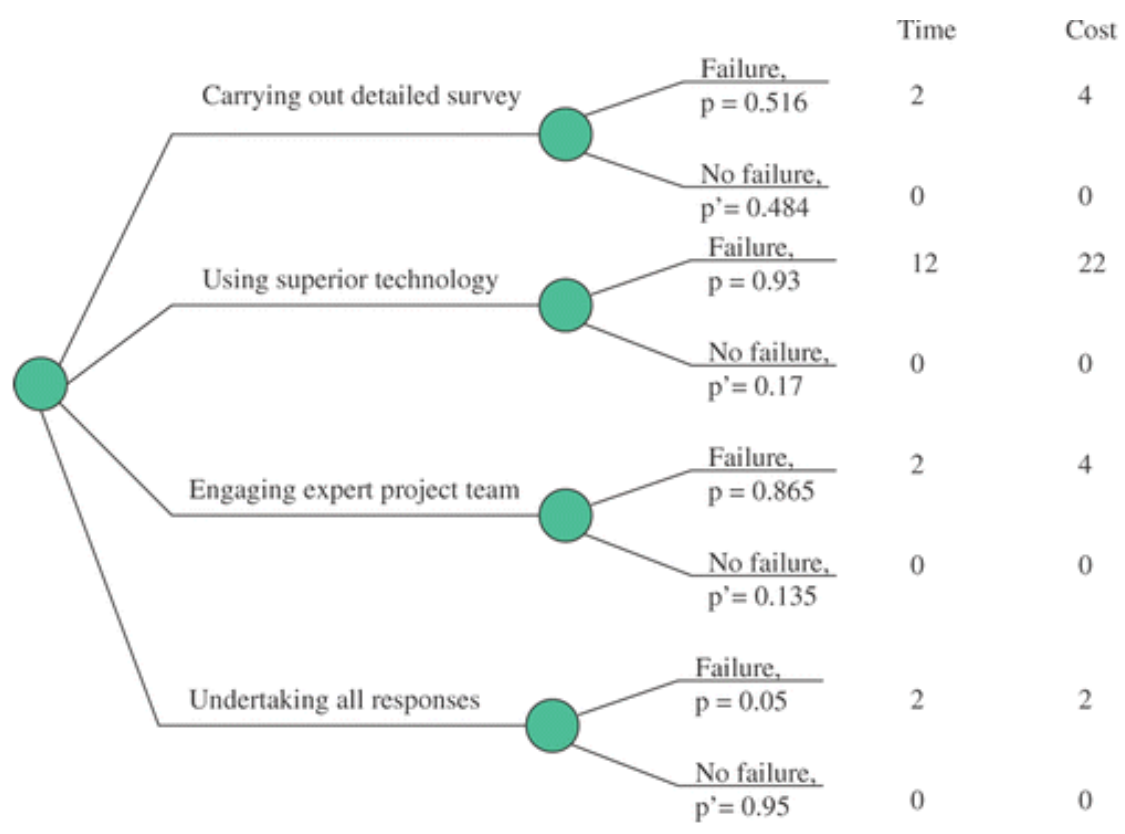

Table 8. The EMV for 'process equipment and piping'.

\begin{tabular}{|c|c|c|c|c|c|c|c|}
\hline \multirow[b]{2}{*}{ Decision alternatives } & \multirow{2}{*}{$\begin{array}{l}\text { Cost (million } \\
\text { US\$) }\end{array}$} & \multirow[b]{2}{*}{ Probability of failure } & \multicolumn{2}{|c|}{ Effect } & \multicolumn{2}{|c|}{ Expected value } & \multirow[b]{2}{*}{$\begin{array}{c}\text { EMV }^{\mathrm{a}} \text { (million } \\
\text { US\$) }\end{array}$} \\
\hline & & & Time (months) & $\begin{array}{c}\text { Cost (million } \\
\text { US\$) }\end{array}$ & Time (months) & $\begin{array}{c}\text { Cost (million } \\
\text { US\$) }\end{array}$ & \\
\hline Do nothing & 0 & & & & 4.81 & 30.28 & 66.36 \\
\hline Carrying out detailed survey & 12 & $0.516^{b}$ & 2 & 4 & 1.03 & 2.06 & 21.80 \\
\hline Using superior technology & 3 & $0.93^{c}$ & 12 & 22 & 11.16 & 20.46 & 107.16 \\
\hline Engaging expert project team & 22 & $0.865^{d}$ & 2 & 4 & 1.73 & 3.46 & 38.44 \\
\hline $\begin{array}{l}\text { Taking all responses as indicated } \\
\text { in table }\end{array}$ & 56 & 0.05 & 2 & 2 & 0.10 & 0.10 & 56.85 \\
\hline
\end{tabular}

Notes: ${ }^{\mathrm{a}}$ Sample EMV calculation for 'do nothing' $=0+4.81 \times 7.5+30.28=66.36$ (Return on investment is 7.5 million US\$ per month, i.e. $15 \%$ of 600 million US\$ per annum); ${ }^{b}$ it is assumed that the 'technical risk' will reduce to zero if 'carrying out detailed survey' responses were undertaken. Therefore, the probability of project failure would be ( $1-0.484$ ),

i.e. 0.516 ; ' similarly, 'superior technology' response will reduce probability of failure by 0.07 . Therefore, the probability of project failure would be ( $1-0.07)$, i.e. 0.93 ; and

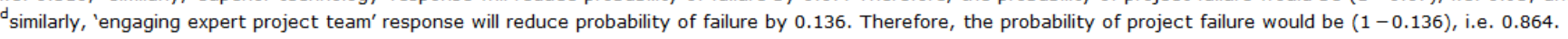

Table 9. The EMV for 'instrumentation and control room'.

\begin{tabular}{|c|c|c|c|c|c|c|c|}
\hline \multirow[b]{2}{*}{ Decision alternatives } & \multirow{2}{*}{$\begin{array}{l}\text { Cost (million } \\
\text { US\$) }\end{array}$} & \multirow{2}{*}{$\begin{array}{l}\text { Probability of } \\
\text { failure }\end{array}$} & \multicolumn{2}{|c|}{ Effect } & \multicolumn{2}{|c|}{ Expected value } & \multirow{2}{*}{$\begin{array}{l}\text { EMV }^{\mathbf{a}} \text { (million } \\
\text { US\$) }\end{array}$} \\
\hline & & & $\begin{array}{l}\text { Time } \\
\text { (months) }\end{array}$ & $\begin{array}{l}\text { Cost (million } \\
\text { US\$) }\end{array}$ & $\begin{array}{c}\text { Time } \\
\text { (months) }\end{array}$ & $\begin{array}{l}\text { Cost (million } \\
\text { US\$) }\end{array}$ & \\
\hline Do nothing & 0 & & & & 4.81 & 30.28 & 66.36 \\
\hline Carrying out detailed survey & 6 & 0.516 & 15 & 40 & 7.74 & 20.64 & 84.69 \\
\hline Using superior technology & 6 & 0.93 & 15 & 40 & 13.95 & 37.20 & 147.83 \\
\hline Engaging expert project team & 16 & 0.865 & 8 & 20 & 6.92 & 17.30 & 85.20 \\
\hline $\begin{array}{l}\text { Taking all responses as indicated in } \\
\text { table }\end{array}$ & 32 & 0.05 & 2 & 8 & 0.10 & 0.40 & 33.15 \\
\hline
\end{tabular}

Note: ${ }^{a}$ EMVs have been derived using similar approach as shown in Table 7. 
Table 10. The EMV for 'power and utilities'.

\begin{tabular}{|c|c|c|c|c|c|c|c|}
\hline \multirow[b]{2}{*}{ Decision alternatives } & \multirow{2}{*}{$\begin{array}{l}\text { Cost (million } \\
\text { US\$) }\end{array}$} & \multirow{2}{*}{$\begin{array}{l}\text { Probability of } \\
\text { failure }\end{array}$} & \multicolumn{2}{|c|}{ Effect } & \multicolumn{2}{|c|}{ Expected value } & \multirow{2}{*}{$\begin{array}{l}\text { EMV }^{\mathbf{a}} \text { (million } \\
\text { US\$) }\end{array}$} \\
\hline & & & $\begin{array}{l}\text { Time } \\
\text { (months) }\end{array}$ & $\begin{array}{l}\text { Cost (million } \\
\text { US\$) }\end{array}$ & $\begin{array}{c}\text { Time } \\
\text { (months) }\end{array}$ & $\begin{array}{l}\text { Cost (million } \\
\text { us\$) }\end{array}$ & \\
\hline Do nothing & 0 & & & & 4.81 & 30.28 & 66.36 \\
\hline Carrying out detailed survey & 3 & 0.516 & 2 & 2 & 1.03 & 1.03 & 11.77 \\
\hline Using superior technology & 1.5 & 0.93 & 2 & 2 & 1.86 & 1.86 & 17.31 \\
\hline Engaging expert project team & 2 & 0.865 & 0.5 & 1 & 0.43 & 0.87 & 6.11 \\
\hline $\begin{array}{l}\text { Taking all responses as indicated in } \\
\text { table }\end{array}$ & 10 & 0.05 & 0.5 & 1 & 0.03 & 0.05 & 10.24 \\
\hline
\end{tabular}

Note: ${ }^{a}$ EMVs have been derived using similar approach as shown in Table 7.

Table 11 gives the decisions emerge from the DTA of risk management:

Table 11. The decisions emerge from the DTA of risk management for each work package.

\begin{tabular}{|l|l}
\hline Work package & Risk response \\
\hline Tank farm and pipelines & Carrying out detailed survey \\
\hline Process equipment and piping & Taking all responses as indicated in Table 5 \\
\hline Instrumentation and control room & Engaging expert project team \\
\hline Power and utilities & Engaging expert project team \\
\hline
\end{tabular}

Total cost for risk responses was US\$ 56 million which was much lower than US\$140 million (if every response as indicated in Table 6 is implemented).

\section{Step 10}

Implementing the responses

The responses as indicated in Table 11 were implemented.

The project was completed in early 2004 with no time and cost overrun. There were a few issues related to engineering and design changes, procurement and commissioning of the hydrocracker units. However, those issues were managed effectively by the project team in collaboration with both the contractors and suppliers. The project team realised the benefit of using the proposed risk management framework. However, they pointed out that identifying the relevant risk factors was very critical. The risk management group had faced the highest complexity while comparing each alternative work package with respect to the risk sub-factors under a particular primary risk criterion. They suggested that a more detailed training workshop about the AHP theory and application prior to the exercise would greatly reduce the duration of the exercise.

\section{Validation of the framework}

The proposed risk management framework was validated for universal application through a questionnaire survey among a few key executives across the Indian oil industry. This was carried out in order to reveal the following:

- the overall significance and importance of risk management for managing projects;

- the acceptability of the method;

- $\quad$ the usability of the proposed framework;

- the comprehensibility of the framework;

- $\quad$ the implementability of the outcomes (the responses);

- the acceptability of the research findings; 
- the adequacy of the stakeholders' involvement in the process of analysing risk;

- the applicability of the methodology and the risk management framework in other projects; and

- $\quad$ future improvement of the model and method of application.

Twenty executives were contacted from 10 companies for the validation survey. Out of which 14 executives agreed to be interviewed. They were briefed about the proposed risk management framework and its application before asking the questions as stated above. In overall response, the participants had been fairly positive about the framework. They had also been in favour of adopting the framework for their project management practices. They have indicated that the basic principle and application of the framework is quite user friendly, the steps are easy to implement and helpful as they consider the decisions of individual stakeholders before reaching a consensus. However, they have agreed that the success of its use would largely depend on the number of stakeholders involved and collective utilisation of their experiences.

\section{Discussion}

The proposed risk management framework using the cause and effect diagram, the AHP, risk map and DTA helps project executives to make decisions dynamically during the project planning phase. This provides an effective monitoring and control mechanism of projects across various levels of management of the organisation. The proposed DSS is a computerised model that uses Expertchoice to analyse the decision situation. Additionally, the sensitivity utility of the AHP provides an opportunity to the risk management group to observe the nature of the model outcome in different alternative decision situations. DTA helps in selecting one among various decision alternatives in a quantitative framework. The following additional benefits are derived from the designed DSS using the AHP and DTA:

1. The AHP provides a flexible and easily understood way to analyse each risk factor with respect to project achievement.

2. The AHP calls for active involvement of project stakeholders in risk analysis and provides a rational basis for probability of project failure.

3. Risk management using the AHP integrates all project stakeholders. Hence, this not only involves them in making group decisions, but also improves team spirit and motivation.

4. The AHP is a suitable approach for reaching a consensus in controversial decisions. Despite the existence of diverging interests, AHP evoked collectively judgements based on a reasonable compromise or consensus.

5. In general, the AHP is used either by application of a questionnaire or by group decision processes. The combination of both uses in this study proved to provide an additional value. The decision-makers can systematically deliberate the specific comparisons before group decision processes take place. This creates an efficient dialogue in order to reach compromises.

6. The collective judgements after group decision processes often deviated from the computed group means of the initial individual judgements. This deviation is an indicator for a high-quality collective decision (Sniezek and Henry 1989).

7. Although the DTA in deciding a specific course of action is not a new method, but logically structures the risk management philosophy by identifying alternative responses in mitigating risk and incorporates management perceptions.

Therefore, risk management using a combined cause and effect diagram, the AHP, risk map and DTA provides an effective means for managing a complex project against time, cost and quality non-achievement.

The proposed risk management using the AHP suffers the following shortcomings:

- $\quad$ Though this study makes an effort to quantify risk by modelling the probability and severity of risk in line with the perception of the experienced project executives, subjectivity could not be reduced to zero. 
A limitation of AHP is its inability to indicate those judgements that need to be revised. Expertchoice gives a recommended revision regardless of whether the recommended value fits within the nine-point scale of AHP. An additional approach is recommended. The study of Genest and Zang (1996) can be a first instigator for a surveyable approach.

- The choice of the scale and whether or not to use normalisations are important issues which should be seen as practical procedural choices whose consequences need to be understood. Although discrete ratio scales such as the 1-9 scale of the AHP can be very helpful in preference elicitation, they are nevertheless problematic as they severely restrict the range and distribution of possible priority vectors. The balanced scale proposed by Salo and Hamalainen (1997) provides an essential improvement in this matter. Even so, the assumption that verbal expressions can be mapped onto numbers in the same way, no matter who is responding and in what context, must be regarded with due caution. The implication of scale selections must be considered explicitly, especially if the results are to be used in a normative sense. Risks associated with scale selection can be mitigated through software tools, which allow the practitioner to compare results based on different scales.

- $\quad$ The real problem with the AHP is the way it aggregates over levels of the hierarchy. This has been well documented in the work of Barzilai (1998), Finan and Hurley (2002) and Belton and Gear (1983). Belton and Gear (1983) introduced the rank reverse phenomenon and most researchers agree that it poses a serious challenge to the AHP.

Nevertheless, on the whole, the AHP has been a useful tool in dealing with multiple factors on different qualitative domains.

The findings and recommendations would be varying across projects, risk perceptions of the managers, organisation's objectives and policies and business environment.

Managing risk across various phases of a project ensures effective management of entire oil refinery construction projects. Although various tools and techniques are available and being practiced for risk identification, analysis and developing responses, an integrated framework helps managing risk effectively, as it provides an analytical framework in a group decision-making framework. Risk identification using experts' opinions, analysing risk using the AHP and statistical analysis, and selecting the best responses using the DTA establishes an integrated cost effective project risk management framework. Large scale construction projects like oil refinery construction, where stakeholders (owner, contractors, suppliers, etc.) experience lots of uncertainties during the planning and implementation phases get considerable benefits using the proposed risk management framework.

\section{Conclusion}

Large scale construction projects (e.g. oil refinery construction) are complex, use state-of-the-art technology, involve many stakeholders and have both considerable environmental and social impacts. Therefore, accomplishment of time, cost and quality of these projects are always uncertain. In this circumstance, in order to ensure successful implementation of projects along with conventional project scope, time and cost management organisations need to formally adopt project risk management practice. Although there are a few risk analysis frameworks, they seldom integrate risk analysis with risk response development. Moreover, they suffer from user friendliness. The proposed combined qualitative and quantitative approach using cause and effect diagram, the AHP, risk map and decision tree analysis helps integrate every process of risk management, namely identification, analysis and response development. The risk management framework involves project personnel for analysis and decision-making in group decision-making framework. It additionally desires management commitment for implementing the responses on risk mitigating measures. This study shows evidences of its successful use for effective project management in Indian oil industry. 
Appendix 1. Determining importance of factors in the AHP [not available in this verison]

Appendix 2. Sample pairwise comparison in subactor level

Appendix 3. Sample pair wise comparison in alternative level

\section{References}

1. AS/NZS ISO 31000. 2009. Risk management - principles and guidelines, Sydney, NSW: AS/NZS.

2. Barzilai, J. 1998. On the decomposition of value functions. Operations Research Letters, 22: 159-170.

3. Belton, $V$ and Gear, T. 1983. On shortcoming of Saaty's method of analytical hierarchies. Omega, 11: 227-230.

4. Canavos, GC. 1984. Applied probability and statistical methods, Boston, MA: Little, Brown \& Co.

5. Chapman, C. 2006. Key points of contention in framing assumptions for risk and uncertainty management. International Journal of Project Management, 24: 303-313.

6. Dey, PK. 2001. Decision support system for project risk management: a case study. Management Decision, 39(8): 634-649.

7. Dey, PK. 2002. Project risk management: a combined analytic hierarchy process and decision tree analysis approach. Cost Engineering Journal, American Associate of Cost Engineering International (AACEI), 44(3): 13-26.

8. Dey, PK. 2006. Integrated approach to project selection using multiple attribute decision-making technique. International Journal of Production Economics, 103: 90-103.

9. Dey, P.K., 2010. Managing project risk using combined analytic hierarchy process and risk map. Applied Soft Computing, 10 (4), 990-1000

10. Dey, PK and Ramcharan, E. 2008. Analytic hierarchy process helps select site for limestone quarry expansion in Barbados. Journal of Environmental Management, 88(4): 1384-1395.

11. Dey, PK, Tabucanon, MT and Ogunlana, SO. 1994. Planning for project control through risk analysis; a case of petroleum pipeline laying project. International Journal of Project Management, 12(1): 23-33.

12. Dilworth, JB. 2000. Operations management: providing value in goods and services, 3rd, Fort Worth, TX: The Dryden Press.

13. Dyer, RF and Forman, EH. 1992. Group decision support with the analytic hierarchy process. Decision Support Systems, 8: 99-124.

14. Finan, JS and Hurley, WJ. 2002. The analytic hierarchy process: can wash criteria be ignored?. Computers and Operations Research, 29(8): 1025-1030.

15. Forman, E.H. and Saaty, T.L., 1983. Expert choice. Pittsburgh, PA: Expert Choice

16. Genest, C and Zhang, SS. 1996. A graphical analysis of ratio - scaled paired conversion data. Management Science, 42(3): 335-349.

17. Golden, BL, Wasli, EA and Harker, PT. 1989. The analytic hierarchy process: applications and studies, New York: Springer Verlag.

18. Islie, G. 1991. A decision support system using judgmental modeling: A case of R\&D in the pharmaceutical industry. IEEE Transactions on Engineering Management, 38(August): 202-209.

19. Kangari, R and Riggs, LS. 1989. Construction risk assessment by linguistics. IEEE Transactions on Engineering Management, 36(2): 126131.

20. Kwak, YH and Anbari, FT. 2009. Analyzing project managementresearch: perspectives from top management journal. International Journal of Project Management, 27: 435-446.

21. Liu, C. 2009. Incentive contract design in competing distribution channels. Production Planning and Control, 20(4): 295-305.

22. Mustafa, MA and AI-Bahar, JF. 1991. Project risk assessment using the analytic hierarchy process. IEEE Transactions on Engineering Management, 38(1): 46-52.

23. Oehmen, J. 2009. System-oriented supply chain risk management. Production Planning and Control, 20(4): 343-361.

24. PMI (Project Management Institute). 2008. A guide to project management body of knowledge, guide, 4th, Upper Darby, PA: PMI.

25. Saaty, TL. 1980. The analytic hierarchy process, New York, NY: McGraw-Hill.

26. Saaty, TL. 1982. Decision making for leaders, New York: Lifetime Learning.

27. Saaty, TL. 1983. Priority setting in complex problems. IEEE Transactions on Engineering Management, EM-30(August): $140-155$.

28. Salo, AA and Hamalainen, RP. 1997. On the measurement of performances in the analytic hierarchy process. Journal of Multi-Criteria Decision Analysis, 6: 309-319.

29. Schatteman, D. 2008. Methodology for integrated risk management and proactive scheduling of construction projects. Journal of Construction Engineering and Management, 134(11): 885-893.

30. Shen, LY, Platten, A and Deng, XP. 2006. Role of public private partnership to manage risks in public sector projects in Hong Kong. International Journal of Project Management, 24(1): 53-65.

31. Sniezek, JA and Henry, RA. 1989. Accuracy and confidence in group judgement. Organizational Behaviour and Human Decision Processes, 43: 1-28.

32. Stefansson, H, Jensson, P and Shah, N. 2009. Procedure for reducing the risk of delayed deliveries in make-to-order production. Production Planning and Control, 20(4): 332-342.

33. Tah, JHM and Carr, V. 2000. A proposal for construction project risk assessment using fuzzy logic. Construction Management and Economics, 18: 491-500. 
34. Thuyet, NV, Ogunlana, SO and Dey, PK. 2007. Risk management in oil and gas construction projects in Vietnam. International Journal of Energy Sector Management, 1(2): 175-194.

35. Tuysuz, F and Kahraman, C. 2006. Project risk evaluation using fuzzy AHP: an application to information technology projects. International Journal of Intelligent System, 21(6): 559-584.

36. Vargas, LG. 1990. An overview of the analytic hierarchy process and its applications. European Journal of Operational Research, 48(1): 28.

37. Wang, SQ, Dulaimi, MF and Aguria, MY. 2004. Risk management framework for construction projects in developing countries. Construction Management and Economics, 22(3): 237-252.

38. William, T. 1995. A classified bibliography of recent research relating to project risk management. European Journal of Operational Research, 85(1): 18-38.

39. Wu, DD and Olson, DL. 2008. Supply risk, simulation and vendor selection. International Journal of Production Economics, 114(2): 646655.

40. Wu, DD and Olson, DL. 2009a. Risk issues in operations: methods and tools. Production Planning Control, 20(4): $293-294$.

41. Wu, DD and Olson, DL. 2009b. Enterprise risk management: small business scorecard analysis. Production Planning Control, 20(4): 362369.

42. Xie, K. 2009. Early-warning management of inner logistics risk in SMEs based on label-card system. Production Planning and Control, 20(4): 306-319.

43. Yang, D, Xiao, T and Shen, H. 2009. Pricing, service level and lot size decisions of a supply chain with risk-averse retailers: implications to practitioners. Production Planning and Control, 20(4): 320-331.

44. Zayed, T, Amer, M and Pan, J. 2008. Assessing risk and uncertainty inherent in Chinese highway projects using AHP. International Journal of Project Management, 26: 406-419. 